\title{
Sistem Pendukung Keputusan Penentuan Handphone Bekas Terbaik Menggunakan Metode Multi-Objective Optimization on The Basis of Ratio Analysis (MOORA)
}

\author{
Ade Septi Rezeki Anggreani Binjori ${ }^{1}$, Hotni Rotua Br Hutapea ${ }^{1}$, Muhammad Syahrizal ${ }^{2}$, Nuning Kurniasih ${ }^{3}$ \\ ${ }^{1}$ Mahasiswa Program Studi Teknik Informatika STMIK Budi Darma, Medan, Indonesia \\ 2 STMIK Budi Darma, Medan, Indonesia \\ ${ }^{3}$ Prodi Ilmu Informasi dan Perpustakaan, Fakultas Ilmu Komunikasi, Universitas Padjadjaran, Bandung, Indonesia
}

\begin{abstract}
Abstrak
Handphone menjadi salah satu kebutuhan yang penting untuk komunikasi saat ini. Perkembangan spesifikasi handphone yang sangat cepat berpengaruh terhadap tingkat pembelian dan penjualan, tidak hanya pada handphone baru tetapi juga pada handphone bekas. Keputusan untuk membeli handphone bekas memerlukan pertimbangan. Penelitian ini bertujuan untuk mengkaji sistem pendukung keputusan penentuan handphone bekas terbaik dengan menggunakan Metode Multi-Objective Optimization on the Basis of Ratio Analysis (MOORA). Hasil penelitian ini menunjukkan MOORA bisa digunakan untuk menentukan nilai bobot setiap atribut, proses perankingan yang akan menyeleksi alternatif handphone terbaik dari sejumlah alternatif yang ada. Sistem Pendukung Keputusan membuat proses penentuan Kualitas handphone bekas lebih efisien dibandingkan dengan sistem manual.
\end{abstract}

Kata kunci: Sistem Pendukung Keputusan, MOORA, Handphone Bekas

\section{Abstract}

Mobile became one of the important needs for communication today. The development of mobile phone specifications very quickly affect the level of purchases and sales, not only on new phones but also on used mobile phones. The decision to buy used mobile phones requires consideration. This study aims to examine the decision support system for determining the best used mobile phone using Multi-Objective Optimization Method on the Basis of Ratio Analysis (MOORA). The results of this study indicate that MOORA can be used to determine the weight value of each attribute, the ranking process that will select the best mobile alternative from a number of alternatives. Decision Support System makes the process of determining the quality of used mobile phone more efficient than the manual system.

Keywords: Decision Support System, MOORA, Handphone

\section{PENDAHULUAN}

Dalam kehidupannya, manusia selalu dihadapkan dengan permasalahan untuk mengambil suatu keputusan. Hal ini terjadi dipenjualan pusat Handphone, permasalahan yang muncul adalah terdapatnya kriteria - kriteria yang menjadi acuan baik itu tipe, model, fitur. Terjadinya permasalahan ini karena adanya faktor-faktor penyebab. Salah satunya, sering ditemukan pembeli handphone yang baru, dan dalam waktu yang cepat terkadang pemakai sudah merasa bosan dan adanya niat membeli handphone yang lebih baik lagi fiturnya dari sebelumnya, hal inilah faktor faktor yang menjadi handphone yang masih layak jual untuk diperjualbelikan kembali.

Disatu sisi, faktor konsumen ingin membeli handphone bekas, disebabkan oleh faktor ekonomi, sehingga konsumen lebih memilih membeli handphone bekas dibanding yang baru.Pesatnya perkembangan komputer dan meningkatnya kegunaan komputer sebagai salah satu alat bantu dalam pengambilan keputusan maka dirancanglah sistem pendukung keputusan[1]. Beragammetode yang dapat diterapkan dalam sistem pendukung keputusan, diantaranya SAW, PROMETHEE, ELECTRE, MOORA, TOPSIS[2][3][4].

Berdasarkan penelitian terdahulu,Syaiful Rokhman, Imam Fahrur Rozi, dan Rosa Andrie Asmara(2017), metode MOORA sangat tepat dalam Sistem Pendukung Keputusan menentukan UKT MAHASISWAdengan menggunakan metode MOORA, tingkat presisi penghitungan nilai rentang antar kelompok UKT lebih baik daripada menggunakan cara penghitungan sebelumnya (karena range tiap UKT sama)[5].

Indra Hidayatulloh, Muhammad Zidny Naf'an(2017) juga melakukan penelitian dengan pendekatan pricequality ratio untuk rekomendasi pemilihan smartphonemenggunakan metode MOORA, rekomendasi peringkat smartphone yang dihasilkan metode MOORA merupakan smartphone dengan kualitas tertinggi[1].

Pada penelitian yang dilakukan ini, peneliti menggunakan metode MOORA untuk menentukan handphone bekas terbaik yang dapat dibeli konsumen

\section{TEORITIS}

\subsection{Metode MOORA (Multi-Objective Optimization on the Basis of Ratio Analysis)}


Metode MOORA merupakan metode dalam pengambilan keputusan dengan mempergunakan multi-Kriteria Brauers (2003). Metode ini diperkenalkan oleh Brauers dan Zavadkas (2006). Beberapa bidang yang mempergunakan aplikasi pengambilan keputusan dengan Metode MOORA antara lain bidang ekonomi, manajemen, kontraktor, bangunan dan desain jalan. Metode MOORA dinilai memiliki tingkat selektifitas yang baik dalam menentukan sebuah alternatif. MOORA melakukan pendekatan secara bersamaan dalam mengoptimalkan dua atau lebih alternative [4][6]. Metode MOORA mudah dipahami dan fleksibel dalam memisahkan objek hingga proses evaluasi kriteria bobot keputusan. Metode MOORA juga memiliki tingkat selektifitas yang baik karena dapat menentukan tujuan dan kriteria yang bertentangan, yaitu kriteria yang bernilai menguntungkan (Benefit) atau yang tidak menguntungkan (Cost).

Langkah - langkah penyelesaian masalah menggunakan metode MOORA[4][1], antara lain :

1. Pembentukan Matriks

$$
x i j=\begin{array}{ccc}
X_{11} & X_{12} & X_{1 n} \\
X_{21} & X_{22} & X_{2 n} \\
\cdot & \cdot & \cdot \\
X_{m 1} & X_{m 2} & X_{m n}
\end{array}
$$

$\mathrm{x}$ adalah nilai kriteria masing-masing kriteria yang direpresentasikan sebagai matriks.

2. Menetukan Matriks Normalisasi

$x \overline{i j}=\frac{x i j}{\sqrt{\sum_{j=1}^{m} x_{i j}^{2}}}$

Rasio Xij menunjukan ukuran ke i dari alternatif pada kriteria ke j, m menunjukan banyaknya jumlah alternatif dan n menunjukan jumlah kriteria. Brauers et al. (2008) menyimpulkan bahwa untuk denominator, pilihan terbaik dari akar kuadrat dari penjumlahan kuadrat dari setiap alternatif perkriteria.

3. Menentukan Matriks Normalisasi terbobot

$y i=\sum_{j=1}^{g} W j X i j^{*}-\sum_{j=g+1}^{n} W_{j} \quad X_{i j}^{*}$

Dalam beberapa kasus, sering mengamati bahwa beberapa kriteria lebih penting daripada lainnya. Untuk menandakan bahwa sebuah kriteria lebih penting, itu bisa dikalikan dengan bobot yang sesuai (Brauers et al. 2009). Dimana Wj adalah bobot dari kriteria ke - j.

4). Menentukan Nilai Preferensi

$\mathrm{y}_{\mathrm{i}=} \sum_{j=1}^{g} W_{j} X_{I J}^{*}-\sum_{j=g+1}^{n} W_{j} X_{i j}^{*}(j=1,2, n)$.

Dengan demikian, alternatif terbaik memiliki nilai yi tertinggi, sedangkan alternatif terburuk memiliki nilai yi terendah.

\section{ANALISA DAN PEMBAHASAN}

Pada analisa masalah ini, akan dibahas proses Pemilihan Handphone Bekas dengan menggunakan metode MultiObjective Optimization on the Basis of Ratio Analysis (MOORA). Langkah pertama yang dilakukan untuk memulai perhitungan dengan metode MOORAadalah menentukan kriteria-kriteria penilaian. Kriteria-kriteria penilaian yang telah ditentukan terdapat pada tabel 1 .

Tabel 1. Kriteria

\begin{tabular}{|c|c|c|c|}
\hline Kriteria & Keterangan & Bobot & Jenis \\
\hline $\mathrm{C}_{1}$ & Ukuran Layar & $25 \%$ & Benefit \\
\hline $\mathrm{C}_{2}$ & Jenis Layar & $15 \%$ & Benefit \\
\hline $\mathrm{C}_{3}$ & Casing & $15 \%$ & Benefit \\
\hline $\mathrm{C}_{4}$ & Harga & $20 \%$ & Cost \\
\hline $\mathrm{C}_{5}$ & Garansi & $25 \%$ & Benefit \\
\hline
\end{tabular}


Langkah selanjutnya menentukan Kriteria Penilaian untuk setiap Alternatif, terdapat pada tabel 2.

Tabel 2. Alternatif

\begin{tabular}{|ll|c|c|c|c|c|}
\hline Alternatif & $\mathrm{C}_{1}$ & $\mathrm{C}_{2}$ & $\mathrm{C}_{3}$ & $\mathrm{C}_{4}$ & $\mathrm{C}_{5}$ \\
\hline Vivo 5 $\left(\mathrm{A}_{1}\right)$ & 5 & 6 & 6 & 800000 & 3 \\
\hline Redmi Note 4 ( $\left.\mathrm{A}_{2}\right)$ & 5 & 5 & 4 & 950000 & 3 \\
\hline Samsung J7 $\left(\mathrm{A}_{3}\right)$ & 5,5 & 4 & 4 & 700000 & 2 \\
\hline Oppo F1 Plus (A4) & 5 & 3 & 6 & 1000000 & 1 \\
\hline
\end{tabular}

Berdasarkan data diatas dapat dibentuk matriks keputusan X sebagai berikut :

$$
X i j=\left[\begin{array}{ccccc}
5 & 6 & 6 & 800000 & 3 \\
5 & 5 & 4 & 950000 & 3 \\
5,5 & 4 & 4 & 700000 & 2 \\
5 & 3 & 6 & 1000000 & 1
\end{array}\right]
$$

Normalisasi matriks $\mathrm{X}$ untuk menghitung nilai masing-masing kriteria.

$$
\begin{aligned}
& C 1=\sqrt{5^{2}+5^{2}+5,5^{2}+5^{2}} \\
& =\sqrt{25+25+30,25+25}=10,259 \\
& \mathrm{~A}_{11}=5 / 10,259=0,4873 \\
& \mathrm{~A}_{21}=5 / 10,259=0,4873 \\
& \mathrm{~A}_{31}=5,5 / 10,259=0,5361 \\
& \mathrm{~A}_{41}=5 / 10,259=0,4873 \\
& C 2=\sqrt{6^{2}+5^{2}+4^{2}+3^{2}} \\
& =\sqrt{36+25+16+9}=9,2736 \\
& \mathrm{~A}_{11}=6 / 9,2736=0,6468 \\
& \mathrm{~A}_{21}=5 / 9,2736=0,5391 \\
& \mathrm{~A}_{31}=4 / 9,2736=0,4313 \\
& \mathrm{~A}_{41}=3 / 9,2736=0,3234 \\
& C 3=\sqrt{6^{2}+4^{2}+4^{2}+6^{2}} \\
& =\sqrt{36+16+16+16}=10,1980 \\
& A_{11}=6 / 10,1980=0,5883 \\
& \mathrm{~A}_{21}=4 / 10,1980=0,3922 \\
& \mathrm{~A}_{31}=4 / 10,1980=0,3922 \\
& A_{41}=6 / 10,1980=0,5883 \\
& C 4=\sqrt{\frac{800000^{2}+950000^{2}+}{700000^{2}+1000000^{2}}} \\
& =\sqrt{\begin{array}{c}
640000000000+902500000000 \\
+490000000000+1000000000000
\end{array}} \\
& =1.741 .407,47
\end{aligned}
$$


$\mathrm{A}_{11}=3 / 4,7958=0,6255$

$\mathrm{A}_{21}=3 / 4,7958=0,6255$

$\mathrm{A}_{31}=2 / 4,7958=0,4170$

$\mathrm{A}_{41}=1 / 4,7958=0,2085$

Maka dapat dilihat matrik ternormalisasi, yaitu:

$\left[\begin{array}{lllll}0,4873 & 0,6468 & 0,5883 & 0,4593 & 0,6255 \\ 0,4873 & 0,5391 & 0,3992 & 0,5455 & 0,6255 \\ 0,5361 & 0,4313 & 0,3992 & 0,4019 & 0,4170 \\ 0,4873 & 0,3234 & 0,5883 & 0,5742 & 0,2085\end{array}\right]$

Selanjutnya menghitung matrik ternormalisasi terbobot, berikut langkah-langkahnya.

$\mathrm{A}_{11=0,25 \times 0,4873=0,1218}$

$\mathrm{A}_{12}=0,25 \times 0,4873=0,1218$

$\mathrm{A}_{13}=0,25 \times 0,5361=0,1340$

$\mathrm{A}_{14}=0,25 \times 0,4873=0,1218$

$\mathrm{A}_{21}=0,15 \times 0,6468=0,0970$

$\mathrm{A}_{22}=0,15 \times 0,5391=0,0808$

$\mathrm{A}_{23}=0,15 \times 0,4313=0,0646$

$\mathrm{A}_{24}=0,15 \times 0,3234=0,0485$

$\mathrm{A}_{31}=0,15 \times 0,5883=0,0882$

$\mathrm{A}_{32}=0,15 \times 0,3992=0,0598$

$\mathrm{A}_{33}=0,15 \times 0,3292=0,0598$

$A_{34}=0,15 \times 0,5883=0,0882$

$\mathrm{A}_{41=} 0,2_{\mathrm{X}} 0,4593=0,0918$

$\mathrm{A}_{42}=0,2 \times 0,5455=0,1091$

$\mathrm{A}_{43}=0,2 \times 0,4019=0,0803$

$\mathrm{A}_{44}=0,2 \mathrm{x} 0,5742=0,1148$

$\mathrm{A}_{51}=0,25 \times 0,6255=0,1563$

$\mathrm{A}_{52}=0,25 \times 0,6255=0,1563$

$\mathrm{A}_{53}=0,25 \times 0,4170=0,1042$

$\mathrm{A}_{54}=0,25 \times 0,2085=0,0521$

Hasilnya dapat dilihat pada matrik berikut:

$\left[\begin{array}{lllll}0,1218 & 0,0970 & 0,0882 & 0,0918 & 0,1563 \\ 0,1218 & 0,0808 & 0,0598 & 0,1091 & 0,1563 \\ 0,1340 & 0,0646 & 0,0598 & 0,0803 & 0,1042 \\ 0,1218 & 0,0485 & 0,0882 & 0,1148 & 0,0521\end{array}\right]$

Tabel 7. Tabel Max dan Min

\begin{tabular}{|c|c|c|c|}
\hline Alternatif & Max $\left(\mathrm{C}_{1}+\mathrm{C}_{2}+\mathrm{C}_{3}\right)$ & $\operatorname{Min}\left(\mathrm{C}_{4}+\mathrm{C}_{5}\right)$ & $\mathrm{Yi}=\mathrm{Max}-\operatorname{Min}$ \\
\hline $\mathrm{A}_{1}$ & $(0,1218+0,0970+0,0882)$ & $0,0918+0,1563$ & 0,0589 \\
\hline $\mathrm{A}_{2}$ & $(0,1218+0,0808+0,0598)$ & $0,1091+0,1563$ & 0,003 \\
\hline $\mathrm{A}_{3}$ & $(0,1340+0,0646+0,0598)$ & $0,0803+0,1042$ & 0,0739 \\
\hline $\mathrm{A}_{4}$ & $(0,1218+0,0485+0,0882)$ & $0,1148+0,0521$ & 0,0916 \\
\hline
\end{tabular}

Tabel 8. Hasil Perangkingan

\begin{tabular}{|c|c|c|}
\hline Alternatif & Yi & Rangking \\
\hline $\mathrm{A}_{1}$ & 0,0589 & 3 \\
\hline
\end{tabular}




\begin{tabular}{|c|c|c|}
\hline Alternatif & Yi & Rangking \\
\hline $\mathrm{A}_{2}$ & 0,003 & 4 \\
\hline $\mathrm{A}_{3}$ & 0,0739 & 2 \\
\hline $\mathrm{A}_{4}$ & 0,0916 & 1 \\
\hline
\end{tabular}

Dari proses menerapkan metode MOORA, maka dihasilkan bahwa $\mathrm{A}_{4}$ sebagai Alternatif terbaik

\section{KESIMPULAN}

Adapun kesimpulan yang diperoleh sebagai berikut:

1. Penerapan Multi-Objective Optimization on the Basis of Ratio Analysis (MOORA)bisa digunakan untuk menentukan nilai bobot setiap atribut, dan dilanjutkan dengan proses perankingan yang akan menyeleksi alternatif terbaik dari sejumlah alternatif yang ada.

2. Sistem Pendukung Keputusan dapat lebih mengefisienkan proses penentuan terhadap Kualitas Handphone Bekas bila dibandingkan dengan sistem manualnya.

\section{REFERENCES}

[1] I. Hidayatulloh and M. Z. Naf'an, "METODE MOORA DENGAN PENDEKATAN PRICE-QUALITY RATIO UNTUK REKOMENDASAI PEMILIHAN SMARTPHONE,” Proceeding SINTAK, pp. 62-68, 2017.

[2] G. J. Maulany, "SISTEM PENDUKUNG KEPUTUSAN UNTUK MENENTUKAN KOMODITI UNGGULAN PADA DAERAH PENGEMBANGAN AGROINDUSTRI MENGGUNAKAN METODE SIMPLE ADDITIVE WEIGHTING (SAW)," J. Ilm. Mustek Anim, vol. 2, no. 2, 2013.

[3] V. M. Athawale and S. Chakraborty, "Facility Location Selection using PROMETHEE II Method," in International Conference on Industrial Engineering and Operations Management Dhaka, 2010, pp. 59-64.

[4] Mesran, R. K. Hondro, M. Syahrizal, A. P. U. Siahaan, R. Rahim, and Suginam, "Student Admission Assessment using Multi- Objective Optimization on the Basis of Ratio Analysis (MOORA)," J. Online Jar. COT POLIPD Student, vol. 10, no. October, 2017.

[5] S. Rokhman, I. F. Rozi, and R. A. Asmara, "Pengembangan sistem penunjang keputusan penentuan ukt mahasiswa dengan menggunakan metode moora studi kasus politeknik negeri malang," vol. 3, no. 4, pp. 36-42, 2017.

[6] M. Ashari, Arini, and F. Mintarsih, "Aplikasi Pemilihan Bibit Budidaya Ikan Air Tawar Dengan Metode MOORA - ENTROPY," Jusnal Sist. Inf., vol. 1, no. 2, 2017.

[7] D. Handoko, M. Mesran, S. D. Nasution, Y. Yuhandri, and H. Nurdiyanto, "Application Of Weight Sum Model (WSM) In Determining Special Allocation Funds Recipients,” IJICS (International J. Informatics Comput. Sci., vol. 1, no. 2, pp. 31-35, 2017.

[8] M. Sumitre and R. Kurniawan, "Rancang Bangun Sistem Pendukung Keputusan Seleksi Penerimaan Tenaga Pengajar Dengan Metode Fuzzy Inference System (FIS) Mamdani," J. Inform., vol. 14, no. 1, pp. 61-71, 2014.

[9] H. Nurdiyanto and Heryanita Meilia, "SISTEM PENDUKUNG KEPUTUSAN PENENTUAN PRIORITAS PENGEMBANGAN INDUSTRI KECIL DAN MENENGAH DI LAMPUNG TENGAH MENGGUNAKAN ANALITICAL HIERARCHY PROCESS (AHP)," in Seminar Nasional Teknologi Informasi dan Multimedia 2016, 2016, no. February, pp. 1-7.

[10] J. Simarmata, Rekayasa Perangkat Lunak. Yogyakarta: Andi, 2010.

[11] J. Simarmata, Pengenalan Teknologi Komputer dan Informasi. Yogyakarta: Andi, 2006.

[12] M. I. Setiawan et al., "Business Centre Development Model of Airport Area in Supporting Airport Sustainability in Indonesia," J. Phys. Conf. Ser., vol. 954, no. 1, p. 12024, 2018.

[13] N. W. Al-Hafiz, Mesran, and Suginam, "Sistem Pendukung Keputusan Penentukan Kredit Pemilikan Rumah Menerapkan MultiObjective Optimization on the Basis of Ratio Analysis ( Moora )," KOMIK (Konferensi Nas. Teknol. Inf. dan Komputer), vol. I, no. 1, pp. 306-309, 2017.

[14] G. Ginting, Fadlina, Mesran, A. P. U. Siahaan, and R. Rahim, “Technical Approach of TOPSIS in Decision Making," Int. J. Recent Trends Eng. Res., vol. 3, no. 8, pp. 58-64, 2017.

[15] P. Karande and S. Chakraborty, "Application of multi-objective optimization on the basis of ratio analysis (MOORA) method for materials selection," Mater. Des., vol. 37, no. 2, pp. 317-324, 2012.

[16] Onur Önay and B. F. Yıldırım, "Evaluation of NUTS Level 2 Regions of Turkey by TOPSIS , MOORA and VIKOR 1," Int. J. Humanit. Soc. Sci., vol. 6, no. 1, pp. 212-221, 2016.

[17] P. Karande, E. K. Zavadskas, and S. Chakraborty, "A study on the ranking performance of some MCDM methods for industrial robot selection problems," Int. J. Ind. Eng. Comput., vol. 7, no. 3, pp. 399-422, 2016.

[18] S. Dian Utami Sutiksno, P. Rufaidah, H. Ali, and W. Souisa, "A Literature Review of Strategic Marketing and The Resource Based View of The Firm," Int. J. Econ. Res., vol. 14, no. 8, pp. 59-73, 2017.

[19] S. Kusumadewi, S. Hartati, A. Harjoko, and R. Wardoyo, Fuzzy Multi-Attribute Decision Making (Fuzzy MADM). Yogyakarta: Graha Ilmu, 2006.

[20] T. Murti, L. A. Abdillah, and M. Sobri, "Sistem Penunjang Keputusan Kelayakan Pemberian Pinjaman Dengan Metode Fuzzy Tsukamoto,” Semin. Nas. Inov. dan Tren (SNIT)2015, pp. 252-256, 2015.

[21] A. J. Putra, L. A. Abdillah, and H. Yudiastuti, "Penentuan sekolah dasar negeri terbaik kota Palembang dengan metode weighted sum model (WSM) dan weighted product model (WPM) menggunakan visual basic.net 2015," Sentikom, no. September, pp. 1-6, 2016. 